\title{
ChemComm
}

Check for updates

Cite this: Chem. Commun., 2021. 57,9272

Received 29th June 2021,

Accepted 16th August 2021

DOI: $10.1039 / \mathrm{d} 1 \mathrm{cc} 03469 \mathrm{c}$

rsc.li/chemcomm

\section{Glassy behaviour of mechanically amorphised ZIF-62 isomorphs†}

\author{
Michael F. Thorne, (D) a Adam F. Sapnik, (D) a Lauren N. McHugh, (D) a \\ Alice M. Bumstead, (D) a Celia Castillo-Blas, (D) a Dean S. Keeble, (D) ${ }^{b}$ \\ Maria Diaz Lopez, ${ }^{b}$ Phillip A. Chater, (D) ${ }^{b}$ David A. Keen (D) ${ }^{c}$ and \\ Thomas D. Bennett (D) *a
}

Zeolitic imidazolate frameworks (ZIFs) can be melt-quenched to form glasses. Here, we present an alternative route to glassy ZIFs via mechanically induced amorphisation. This approach allows various glassy ZIFs to be produced in under $\mathbf{3 0}$ minutes at room temperature, without the need for melt-quenching.

Metal-organic frameworks (MOFs) are hybrid materials consisting of inorganic nodes connected through organic linkers. ${ }^{1}$ Major applications proposed for MOFs include gas storage, separation, ${ }^{2}$ and heterogeneous catalysis. ${ }^{3}$

Several members of a sub-category of MOFs, zeolitic imidazolate frameworks (ZIFs), have been shown to undergo melting, and form liquids of identical composition to their crystalline parent materials. ${ }^{4}$ ZIF-62 $\left[\mathrm{M}(\mathrm{Im})_{2-x}(\mathrm{bIm})_{x}\right]$ where $x \geq 0.05$, $\mathrm{M}=\mathrm{Zn}^{2+}$ or $\mathrm{Co}^{2+}, \mathrm{Im}=\left[\mathrm{C}_{3} \mathrm{H}_{3} \mathrm{~N}_{2}\right]^{-}$and $\mathrm{bIm}=\left[\mathrm{C}_{7} \mathrm{H}_{5} \mathrm{~N}_{2}\right]^{-}$, exhibits a melting event at $c a .430{ }^{\circ} \mathrm{C}$ to form a ZIF liquid. ${ }^{5}$ Quenching of this liquid yields a glass ( $a_{g}$ ZIF-62, $a_{g}=$ melt-quenched glass), with a continuous random network topology akin to that of amorphous $\mathrm{SiO}_{2}{ }^{5-9}$

A mechanochemical (solid-state milling) approach to crystalline ZIF-62 has recently been reported. ${ }^{10}$ This, unlike conventional solvothermal synthesis, allows for direct stoichiometric control over both ligand and metal ratios. ${ }^{10}$ This facilitates control over melting points $\left(T_{\mathrm{m}}\right)$ and subsequent glass transition temperatures $\left(T_{\mathrm{g}}\right)$, i.e. second order phase transitions, in which an amorphous material transforms to a liquid-like state upon heating.

The formation of ZIF glasses by melt-quenching is limited by the necessity for appropriate crystalline framework densities and

\footnotetext{
${ }^{a}$ Department of Materials Science and Metallurgy, University of Cambridge, 27 Charles Babbage Road, Cambridge, Cambridgeshire, CB3 OFS, UK. E-mail: tdb35@cam.ac.uk

${ }^{b}$ Diamond Light Source Ltd, Diamond House, Harwell Campus, Didcot, Oxfordshire, OX11 ODE, UK

${ }^{c}$ ISIS Facility, Rutherford Appleton Laboratory, Harwell Campus, Didcot, Oxfordshire, OX11 OQX, UK

$\dagger$ Electronic supplementary information (ESI) available. See DOI: 10.1039/ d1 1 c $03469 \mathrm{c}$
}

thermally stable linkers. ${ }^{11}$ The production of glassy materials via mechanical force has been demonstrated for metallic alloy glasses, ${ }^{12}$ organic pharmaceuticals, ${ }^{13}$ and two dimensional coordination polymers. ${ }^{14}$ For example, the two dimensional coordination polymer system $\left[\mathrm{M}(1,2,4 \text {-triazole })_{2}\left(\mathrm{H}_{2} \mathrm{PO}_{4}\right)_{2}\right]$ (where $\mathrm{M}=\mathrm{Cd}^{2+}, \mathrm{Cr}^{2+}$, or $\mathrm{Mn}^{2+}$ ) can be vitrified by either melt-quenching or by the application of mechanical force. ${ }^{15}$

Mechanical amorphisation of ZIFs has been studied for archetypal materials such as ZIF-4 $\left[\mathrm{Zn}(\mathrm{Im})_{2}\right]$, and ZIF-8 $\left[\mathrm{Zn}(\mathrm{mIm})_{2}\right]$ mIm $=\left[\mathrm{C}_{4} \mathrm{H}_{5} \mathrm{~N}_{2}\right]^{-}$, although a detailed investigation into the thermal response of mechanically amorphised systems has yet to be performed. ${ }^{16,17}$ Here, we investigate the mechanochemical amorphisation of ZIF-62 and its subsequent glass like behaviour.

We adapted the previously reported mechanosynthesis of ZIF62 to access a series of materials with increasing bIm : Im ratio. ${ }^{10,18}$ The maximum reported bIm:Im ratio in prior mechanochemical syntheses of ZIF-62 was $\left[\mathrm{Zn}(\mathrm{Im})_{1.75}(\mathrm{bIm})_{0.25}\right]{ }^{10}$ whereas that for solution phase synthesis was $\left[\mathrm{Zn}(\mathrm{Im})_{1.65}(\mathrm{bIm})_{0.35}\right]{ }^{5,19}$ Here, crystalline $\left[\mathrm{Zn}(\mathrm{Im})_{1.70}(\mathrm{bIm})_{0.30}\right]$ was successfully formed after 30 minutes of grinding. However, further increasing the bIm content by 0.05 resulted in an amorphous product, with the formula $a_{m}\left[\mathrm{Zn}(\operatorname{Im})_{1.65}(b I m)_{0.35}\right]\left(a_{m}=\right.$ mechanically amorphised $)$, being produced after 30 minutes of grinding (Fig. 1a and Fig. S1, ESI $†$ ).

Thermogravimetric analysis (TGA), differential scanning calorimetry (DSC), optical microscopy, and thermomechanical analysis (TMA) were conducted on $\mathrm{a}_{\mathrm{m}}\left[\mathrm{Zn}(\mathrm{Im})_{1.65}(\mathrm{bIm})_{0.35}\right]$ (Fig. 1) (Fig. S2-S5, ESI $\dagger$ ). Interestingly, upon a first heating upscan in the DSC, $\mathrm{a}_{\mathrm{m}}\left[\mathrm{Zn}(\mathrm{Im})_{1.65}(\mathrm{bIm})_{0.35}\right]$ exhibited a glass transition $\left(T_{\mathrm{g} 1}=318{ }^{\circ} \mathrm{C}\right)$. This $T_{\mathrm{g} 1}$ is evidence of glassy behaviour and highlights the different thermal response of this material when compared to crystalline ZIF-62. Crystalline ZIF-62 displays a $T_{\mathrm{m}}$ on a first heating scan, at significantly higher temperatures than $T_{\mathrm{g} 1}$ seen here. ${ }^{10}$ To further investigate the glassy behaviour of $\mathrm{a}_{\mathrm{m}}\left[\mathrm{Zn}(\mathrm{Im})_{1.65}(\mathrm{bIm})_{0.35}\right]$, the softening temperature $\left(T_{\mathrm{s}}\right)$ was determined from TMA. This confirmed a brittle to soft transition at $T_{\mathrm{g} 1}$, with the $T_{\mathrm{s}}$ for $\mathrm{a}_{\mathrm{m}}\left[\mathrm{Zn}(\operatorname{Im})_{1.65}(\mathrm{bIm})_{0.35}\right]$ being $322{ }^{\circ} \mathrm{C}$ (Fig. S4, ESI $\dagger$ ). This $\mathrm{a}_{\mathrm{m}}$ ZIF-62 sample has a completely different thermal history to 
a

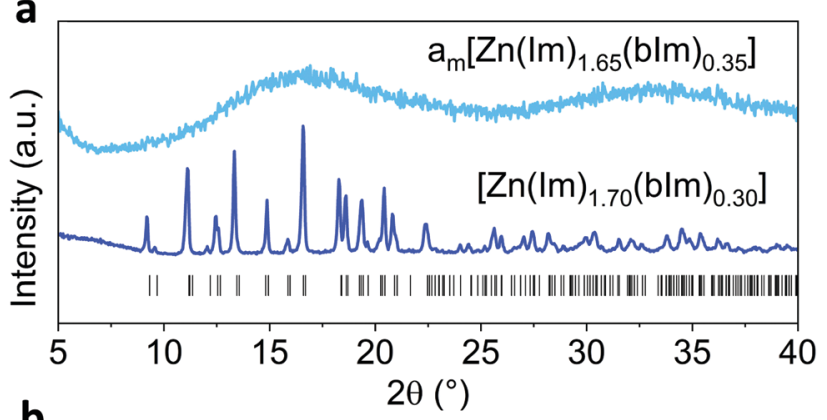

b

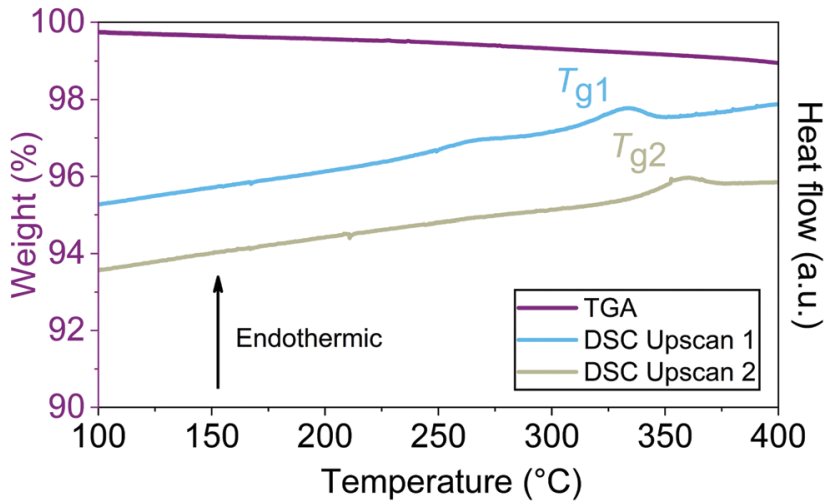

Fig. 1 (a) Powder X-ray diffraction (PXRD) of $a_{m}\left[\mathrm{Zn}(\operatorname{lm})_{1.65}(\mathrm{~b} / \mathrm{m})_{0.35}\right]$, $\left[\mathrm{Zn}(\mathrm{Im})_{1.70}(\mathrm{~b} / \mathrm{m})_{0.30}\right]$ with calculated Bragg positions for ZIF-62. (b) TGA-DSC scans showing thermal response of $a_{m}\left[\mathrm{Zn}(\mathrm{Im})_{1.65}(\mathrm{~b} / \mathrm{m})_{0.35}\right]$ during heating upscan 1 and 2. Full TGA and DSC scans are available, including a DSC upscan of unevacuated $a_{m}\left[\mathrm{Zn}(\mathrm{Im})_{1.65}(\mathrm{~b} / \mathrm{m})_{0.35}\right]$ to identify solvent loss events (Fig. S2 and S3, ESI†).

melt-quenched ZIF glasses seen previously, ${ }^{10}$ or for the meltquenched $\mathrm{a}_{\mathrm{g}}\left[\mathrm{Zn}(\mathrm{Im})_{1.70}(\mathrm{bIm})_{0.30}\right]$ reported here (Fig. S6-S10, ESI†). ${ }^{5,10} T_{\mathrm{g}}$ values for melt-quenched systems are usually reported from the second DSC heating scan, as the first heating scan is required to melt the crystalline material. ${ }^{10}$

Given the dependence of $T_{\mathrm{g}}$ on thermal history, ${ }^{20}$ a second heat treatment to $450{ }^{\circ} \mathrm{C}$ was performed on $\mathrm{a}_{\mathrm{m}}\left[\mathrm{Zn}(\operatorname{Im})_{1.65}\right.$ $\left.(\mathrm{bIm})_{0.35}\right]$ to give the material equivalent thermal history to melt-quenched systems. ${ }^{10}$ This allowed for a more consistent comparison between $\mathrm{a}_{\mathrm{m}}\left[\mathrm{Zn}(\mathrm{Im})_{1.65}(\mathrm{bIm})_{0.35}\right]$ and meltquenched glasses. After this second heat treatment, a second glass transition temperature $\left(T_{\mathrm{g}_{2}}\right)$ was observed (Fig. 1b). This $T_{\mathrm{g} 2}=347{ }^{\circ} \mathrm{C}$ continues the trend as seen for melt-quenched $\mathrm{a}_{g}\left[\mathrm{Zn}(\operatorname{Im})_{2-x}(\mathrm{bIm})_{x}\right]$ systems previously reported experimentally (Fig. 2), ${ }^{19}$ and predicted from topological constraint theory. ${ }^{21,22}$ Consequently, after initial heat treatment, $\mathrm{a}_{\mathrm{m}}\left[\mathrm{Zn}(\mathrm{Im})_{1.65}\right.$ $(\mathrm{bIm})_{0.35}$ ] may now be considered equivalent to a meltquenched glass (Fig. 2). From this point onwards, $\mathrm{a}_{\mathrm{m}}\left[\mathrm{Zn}(\mathrm{Im})_{1.65}\right.$ $\left.(\mathrm{bIm})_{0.35}\right]$ after initial heat treatment will therefore be denoted as $\mathrm{a}_{\mathrm{g}}\left[\mathrm{Zn}(\operatorname{Im})_{1.65}(\mathrm{bIm})_{0.35}\right]$, for consistency.

The different $T_{\mathrm{g}}$ values for $\mathrm{a}_{\mathrm{m}}\left[\mathrm{Zn}(\operatorname{Im})_{1.65}(\mathrm{bIm})_{0.35}\right]$, before and after heat treatment, indicate structural changes may have occurred during heating. A possible property of the material which may change upon heat treatment is its skeletal density. The $\mathrm{He}$ pycnometric densities of $\mathrm{a}_{\mathrm{m}}\left[\mathrm{Zn}(\operatorname{Im})_{1.65}(\mathrm{bIm})_{0.35}\right]$ and $\mathrm{a}_{\mathrm{g}}\left[\mathrm{Zn}(\operatorname{Im})_{1.65}\right.$ $\left.(\mathrm{bIm})_{0.35}\right]$ (i.e. before and after heat treatment) are similar, with

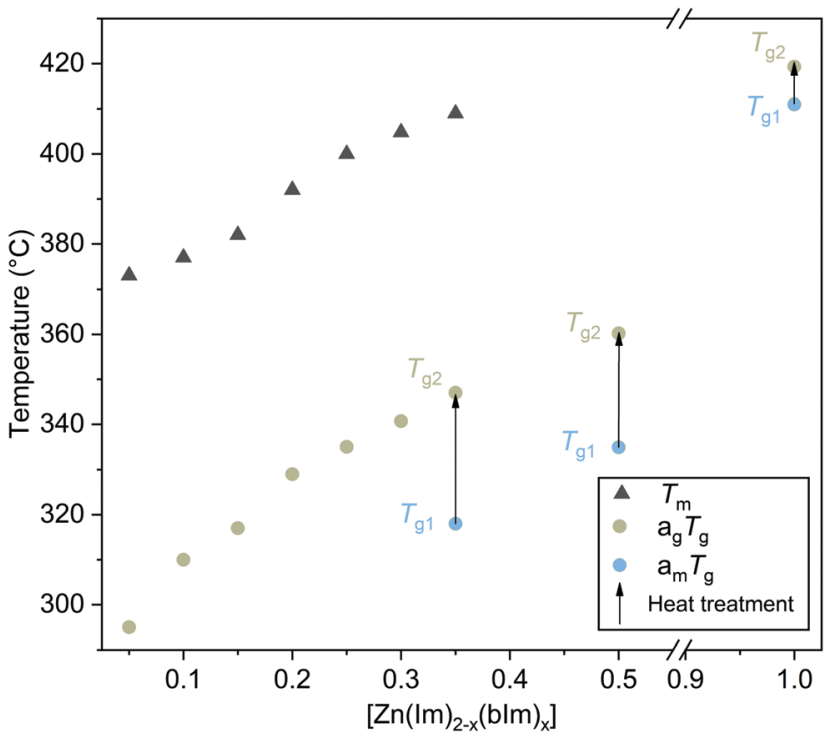

Fig. $2 T_{m}$ values (grey) for various $\left[\mathrm{Zn}(\mathrm{Im})_{2-x}(\mathrm{~b} / \mathrm{m})_{x}\right]$ formulations showing an increase in $T_{m}$ offset with $x$. Melt-quenched glass $T_{\mathrm{g}}\left(\mathrm{a}_{\mathrm{g}} T_{\mathrm{g}}\right)$ values (green) for various $a_{g}\left[\mathrm{Zn}(\mathrm{Im})_{2-x}(\mathrm{~b} / \mathrm{m})_{x}\right]$ formulations. Mechanically amorphised $T_{g}\left(a_{m} T_{g}\right)$ values (blue) for $a_{m}\left[\mathrm{Zn}(\mid \mathrm{Im})_{2-x}(\mathrm{~b} / \mathrm{m})_{x}\right]$ systems, and their transformation to $\mathrm{a}_{\mathrm{g}} T_{\mathrm{g}}$ after heat treatment (arrows). The $T_{\mathrm{m}}$ for $x=0.35$ is from crystalline $\left[\mathrm{Zn}(\mathrm{Im})_{1.65}(\mathrm{~b} / \mathrm{m})_{0.35}\right]$ after 15 minutes of mechanosynthesis.

values of $1.584( \pm 0.002) \mathrm{g} \mathrm{cm}^{-3}$ and $1.576( \pm 0.003) \mathrm{g} \mathrm{cm}^{-3}$ respectively (Fig. S11, ESI $\dagger$ ). This suggests the increase in $T_{\mathrm{g}}$ is not due to a significant change in skeletal density.

To investigate whether pore volume differences can be observed between $\mathrm{a}_{\mathrm{m}}\left[\mathrm{Zn}(\mathrm{Im})_{1.65}(\mathrm{bIm})_{0.35}\right]$ and $\mathrm{a}_{\mathrm{g}}\left[\mathrm{Zn}(\mathrm{Im})_{1.65}\right.$ $\left.(\mathrm{bIm})_{0.35}\right] \quad \mathrm{CO}_{2}$ gas sorption experiments were performed (Fig. S12, ESI $\dagger$ ). This is important as the free space available in the pores of the materials may affect the steric freedom of the linkers, and therefore influence $T_{\mathrm{g}}{ }^{23}$ Both materials showed almost identical isotherms, with a maximum $\mathrm{CO}_{2}$ uptake of $23.6 \mathrm{~cm}^{3} \mathrm{~g}^{-1}$ in both cases. Further to this, the pore widths were determined to be $3.6 \AA$ in both cases, and maximum pore volume of $0.043 \mathrm{~cm}^{3} \mathrm{~g}^{-1}$ was found for $\mathrm{a}_{\mathrm{m}}\left[\mathrm{Zn}(\mathrm{Im})_{1.65}(\mathrm{bIm})_{0.35}\right]$ and $\mathrm{a}_{\mathrm{g}}\left[\mathrm{Zn}(\mathrm{Im})_{1.65}(\mathrm{bIm})_{0.35}\right]$. These similarities in pore size and volume rule out changes in pore space causing changes in $T_{\mathrm{g}}$. Additionally, the $\mathrm{CO}_{2}$ isotherms do not show a large difference in hysteresis, and as no mass loss from potential $\mathrm{Zn}-\mathrm{CO}_{2} / \mathrm{Zn}-\mathrm{H}_{2} \mathrm{O}$ sites is seen in TGA, it is unlikely that a substantial number of defects caused by severed $\mathrm{Zn}-\mathrm{N}$ bonds are present in $\mathrm{a}_{\mathrm{m}}\left[\mathrm{Zn}(\mathrm{Im})_{1.65}(\mathrm{bIm})_{0.35}\right]$ (Fig. S2, ESI†).

The temperature difference between $T_{\mathrm{g} 1}$ and $T_{\mathrm{g} 2}$ is akin to the difference between $T_{\mathrm{m}}$ in mechanochemically and solvothermally produced crystalline ZIF-62 systems with identical chemical composition. For example, the $T_{\mathrm{m}}$ offset of mechanochemically produced crystalline ZIF-62 is lower than solvothermally produced ZIF-62 in various different reports, yet the resultant $T_{\mathrm{g}} \mathrm{s}$ are identical. ${ }^{5,10,24}$ This is assumed to be a particle size effect seen when performing DSC at a constant heating rate, on the same material with different particle sizes.

Here, scanning electron microscopy (SEM) revealed the production of nanoscale $\mathrm{a}_{\mathrm{m}}\left[\mathrm{Zn}(\mathrm{Im})_{1.65}(\mathrm{bIm})_{0.35}\right]$ particles 
directly after mechanosynthesis. This was followed by their coalescence to form connected globular particles larger than $10 \mu \mathrm{m}$, after heat treatment to form $\mathrm{a}_{\mathrm{g}}\left[\mathrm{Zn}(\mathrm{Im})_{1.65}(\mathrm{bIm})_{0.35}\right]$ (Fig. S13, ESI $\dagger$ ). Therefore, the difference in $T_{\mathrm{g} 1}$ and $T_{\mathrm{g} 2}$ is likely a kinetic effect seen in DSC caused by particle agglomeration, rather than a thermodynamic lowering of $T_{\mathrm{g}}$ caused by structural changes in the amorphous materials. To further investigate the change from $T_{\mathrm{g} 1}$ to $T_{\mathrm{g} 2}$, with particle agglomeration, a set of DSC experiments on $\mathrm{a}_{\mathrm{m}}\left[\mathrm{Zn}(\mathrm{Im})_{1.65}(\mathrm{bIm})_{0.35}\right]$ were performed (Fig. S14 and S15, ESI $\dagger$ ). These results show $T_{\mathrm{g}_{2}}$ is only dependant on maximum temperature during heating, and therefore support the hypothesis that particle agglomeration affects $T_{\mathrm{g} 2}$.

ZIF-62 is a compositional series $\left[\mathrm{Zn}(\operatorname{Im})_{2-x}(\mathrm{bIm})_{x}\right]$, with the lower limit of $x=0.05 .^{5,10}$ However, the upper limit of $x$ has never been identified. ${ }^{25}$ To further investigate mechanically induced amorphisation, and determine an upper limit of $x$ for $\mathrm{a}_{\mathrm{m}}$ ZIF-62, the bIm content was increased in the mechanosynthesis. This yielded $\mathrm{a}_{\mathrm{m}}\left[\mathrm{Zn}(\mathrm{Im})_{1.5}(\mathrm{bIm})_{0.5}\right]$ and $\mathrm{a}_{\mathrm{m}}\left[\mathrm{Zn}(\mathrm{Im})_{1.0}(\mathrm{bIm})_{1.0}\right]$, with attempts to yield $x>1.0$ resulting in partial ZIF-7 synthesis (Fig. S16-S18, ESI $\dagger$ ). These high bIm content $\mathrm{a}_{\mathrm{m}}$ ZIF-62 systems also yielded a $T_{\mathrm{g} 1}$ and subsequent higher $T_{\mathrm{g} 2}$ values after heat treatment to form their equivalent $\mathrm{a}_{\mathrm{g} Z \mathrm{ZIF}-62}$ systems. These $T_{\mathrm{g} 2}$ values also agree with an increase of $T_{\mathrm{g}}$ with bIm content (Fig. 2 and Fig. S19-S24, ESI $\dagger)$. The $T_{\mathrm{g} 1}$ values for $\mathrm{a}_{\mathrm{m}}\left[\mathrm{Zn}(\mathrm{Im})_{1.50}(\mathrm{bIm})_{0.50}\right]$ and $\mathrm{a}_{\mathrm{m}}\left[\mathrm{Zn}(\mathrm{Im})_{1.0}(\mathrm{bIm})_{1.0}\right]$ were $335{ }^{\circ} \mathrm{C}$ and $411{ }^{\circ} \mathrm{C}$ respectively. The $T_{\mathrm{g} 2}$ values were of the respective $\mathrm{a}_{\mathrm{g}} \mathrm{ZIFs}$ were $360{ }^{\circ} \mathrm{C}$ and $419{ }^{\circ} \mathrm{C}$. The $T_{\mathrm{g} 2}$ value for $\mathrm{a}_{\mathrm{g}}\left[\mathrm{Zn}(\mathrm{Im})_{1.0}(\mathrm{bIm})_{1.0}\right]$ represents by far the highest $T_{\mathrm{g}}$ value ever measured for a ZIF glass, driven by its high bIm content. ${ }^{23}$

To understand the production of $\mathrm{a}_{\mathrm{m}} \mathrm{ZIFs}$, an ex situ kinetics study on $\mathrm{a}_{\mathrm{m}}\left[\mathrm{Zn}(\mathrm{Im})_{1.65}(\mathrm{bIm})_{0.35}\right]$ formation was performed (Fig. S25 and S26, ESI $\dagger$ ). This showed initial production of crystalline $\left[\mathrm{Zn}(\mathrm{Im})_{1.65}(\mathrm{bIm})_{0.35}\right]$. The $\left[\mathrm{Zn}(\mathrm{Im})_{1.65}(\mathrm{bIm})_{0.35}\right]$ remained crystalline until mechanically induced amorphisation after 22 minutes, with no further change in the diffraction pattern after 30 minutes.

We note that crystalline ZIFs with the cag topology, such as ZIF-62 and ZIF-4, have 4 and 8-membered rings of $\mathrm{ZnN}_{4}$ tetrahedra. ${ }^{26}$ In ZIF- 4 there are no bIm linkers, however, when bIm linkers are included as in ZIF-62, the bulky six membered aromatic rings of bIm may exclude DMF from the pore space of the ZIF (Fig. S27, ESI $\dagger$ ). When the bIm content is increased, such as in the case of $\left[\mathrm{Zn}(\mathrm{Im})_{1.65}(\mathrm{bIm})_{0.35}\right]$, a larger amount of bIm linkers will occupy the free space within the pores. We hypothesise that increasing the bIm content of ZIF-62 is correlated with a reduction in DMF content within the ZIF structure. This was confirmed by TGA measurements, which showed a lower mass loss due to solvent evaporation from ZIF62 samples with a higher bIm content (Fig. S28, ESI $\dagger$ ). The lower level of DMF per mol of $\mathrm{Zn}$ in $\left[\mathrm{Zn}(\mathrm{Im})_{1.65}(\mathrm{bIm})_{0.35}\right]$, with respect to $\left[\mathrm{Zn}(\mathrm{Im})_{1.75}(\mathrm{bIm})_{0.25}\right]\left(19.74 \mathrm{~g} \mathrm{~mol}^{-1}\right.$ vs. $\left.26.51 \mathrm{~g} \mathrm{~mol}^{-1}\right)$, may reduce the ability of the material to withstand mechanical collapse. This has previously been found for solvated and fully evacuated ZIFs. ${ }^{27}$ Further to this, DSC was performed on crystalline $\left[\mathrm{Zn}(\mathrm{Im})_{1.65}(\mathrm{bIm})_{0.35}\right]$ after 15 minutes of mechanosynthesis (Fig. S29, ESI $\dagger$ ). This showed a $T_{\mathrm{m}}$ of $409{ }^{\circ} \mathrm{C}$,
(Fig. 2) and $T_{\mathrm{g}}$ of $346{ }^{\circ} \mathrm{C}$. The enthalpy of fusion increases with bIm content in ZIF-62 systems, therefore the enthalpy of fusion for crystalline $\left[\mathrm{Zn}(\mathrm{Im})_{1.65}(\mathrm{bIm})_{0.35}\right]$ was expected to be higher than $\left[\mathrm{Zn}(\mathrm{Im})_{1.70}(\mathrm{bIm})_{0.30}\right]^{24}$ However here, the enthalpy of fusion for crystalline $\left[\mathrm{Zn}(\mathrm{Im})_{1.65}(\mathrm{bIm})_{0.35}\right]$ was far lower than $\left[\mathrm{Zn}(\operatorname{Im})_{1.70}\right.$ $\left.(\mathrm{bIm})_{0.30}\right]\left(7.57 \mathrm{~J} \mathrm{~g}^{-1}\right.$ vs. $12.57 \mathrm{~J} \mathrm{~g}^{-1}$ ) indicating a lower level of crystallinity in $\left[\mathrm{Zn}(\mathrm{Im})_{1.65}(\mathrm{bIm})_{0.35}\right]$. Therefore, we hypothesise that the amorphisation of $\left[\mathrm{Zn}(\mathrm{Im})_{1.65}(\mathrm{bIm})_{0.35}\right]$ is due to lower DMF content in the pores, and also lower crystallinity with respect to other mechanosynthetic ZIF-62 systems.

To investigate the local and long range structure in $\mathrm{a}_{\mathrm{m}}\left[\mathrm{Zn}(\mathrm{Im})_{1.65}\right.$ $\left.(\mathrm{bIm})_{0.35}\right]$ upon heat treatment to form $\mathrm{a}_{\mathrm{g}}\left[\mathrm{Zn}(\mathrm{Im})_{1.65}(\mathrm{bIm})_{0.35}\right]$, variable temperature pair distribution function (VT PDF) data was collected (Fig. 3 and Fig. S30-S36, ESI $\dagger$ ), as well as calculations to aid in the assignment of the peaks (Fig. S34-S36, ESI $\dagger$ ). To assist in the refinement of the structure against the experimental $D(r)$, modifications were made to a previously published ZIF-62 CIF (see methods). ${ }^{10}$ The calculated $D(r)$ showed a good agreement with experimental data for $\left[\mathrm{Zn}(\mathrm{Im})_{1.65}(\mathrm{bIm})_{0.35}\right]$ at room temperature (Fig. S34, ESI $\dagger$ ), and the exported structure showed a chemically sensible unit cell (Fig. S35, ESI $\dagger$ ). From this, the weighted partial PDF correlations from individual atom-atom pairs, $g_{i j}(r)$, can be obtained. ${ }^{28}$ From these correlations, $D(r)$ peak assignments can be made (Fig. S36, ESI $\dagger$ ).

Upon heat treatment to $400{ }^{\circ} \mathrm{C}$, there was no evidence of crystallisation, with no evidence of long-range order observed at any temperature in the $D(r)$ (Fig. 3), or sharp Bragg peaks in the $S(Q)$ (Fig. S33, ESI $\dagger$ ). The VT PDF highlights how similar the $\mathrm{a}_{\mathrm{m}} \mathrm{ZIF}$ and $\mathrm{a}_{\mathrm{g}} \mathrm{ZIF}$ are on a structural level, as no major changes before and after heat treatment can be seen in the $D(r)$ or $S(Q)$.

To further illustrate mechanically induced amorphisation in ZIFs, a similar process of increasing large linker content for the glass-forming ZIF-UC-5 compositional series, $\left[\mathrm{Zn}(\mathrm{Im})_{2-x}(\mathrm{ClbIm})_{x}\right]$ (where ClbIm $=\left[\mathrm{C}_{7} \mathrm{H}_{4} \mathrm{ClN}_{2}\right]^{-}$) was performed (Fig. S37-S40, ESI $\dagger$ ). ${ }^{10,29}$ Interestingly, the switch from forming crystalline ZIFs to

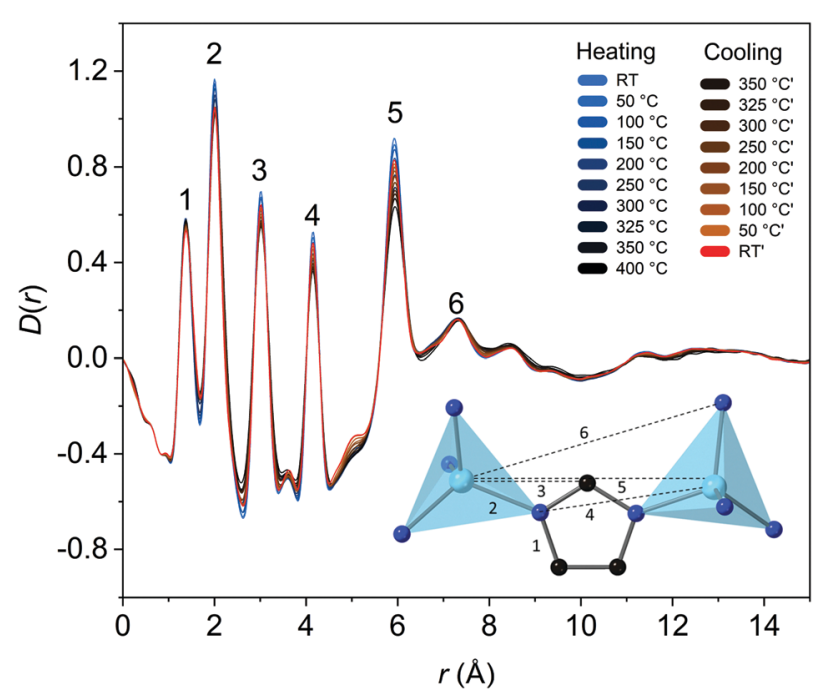

Fig. $3 D(r)$ of $a_{m}\left[\mathrm{Zn}(\mid \mathrm{m})_{1.65}(\mathrm{blm})_{0.35}\right]$ during heat treatment showing no long range order throughout, and retention of the $\mathrm{Zn}-\mathrm{Im}-\mathrm{Zn}$ bonding unit. Inset shows the characteristic correlations of a $\mathrm{Zn}-\mathrm{Im}-\mathrm{Zn}$ bonding unit. 
producing $\mathrm{a}_{\mathrm{m}}$ ZIFs occurred at $x=0.30$ as opposed to $x=0.35$ in the case ZIF-62 (Fig. S41, ESI $\dagger$ ). The sterically larger ClbIm in ZIF-UC-5 may exclude a greater amount of solvent from the pores of the ZIF-UC-5 relative to bIm in ZIF-62. ${ }^{30}$ This may be the reason for the production of $\mathrm{a}_{\mathrm{m}}\left[\mathrm{Zn}(\mathrm{Im})_{1.70}(\mathrm{ClbIm})_{0.30}\right]$ when the equivalent ZIF-62 system remains crystalline after $30 \mathrm{~min}$ utes of grinding. Further to this, $\mathrm{a}_{\mathrm{m}}\left[\mathrm{Zn}(\mathrm{Im})_{1.65}(\mathrm{ClbIm})_{0.35}\right]$ was formed after 30 minutes of mechanosynthesis.

An ex situ kinetics study of $\mathrm{a}_{\mathrm{m}}\left[\mathrm{Zn}(\operatorname{Im})_{1.65}(\mathrm{ClbIm})_{0.35}\right]$ formation revealed a similar trend to $\mathrm{a}_{\mathrm{m}}\left[\mathrm{Zn}(\mathrm{Im})_{1.65}(\mathrm{bIm})_{0.35}\right]$ (Fig. S41, ESI $\dagger$ ). As for $\mathrm{a}_{\mathrm{m}}\left[\mathrm{Zn}(\operatorname{Im})_{1.65}(\mathrm{bIm})_{0.35}\right], \mathrm{a}_{\mathrm{m}}\left[\mathrm{Zn}(\operatorname{Im})_{1.65}\right.$ $\left.(\mathrm{ClbIm})_{0.35}\right]$ was amorphous after 30 minutes of grinding after going through an intermediate cag topology crystalline state.

Thermal analysis confirmed the glassy behaviour of both $\mathrm{a}_{\mathrm{m}}$ ZIF-UC-5 samples (Fig. S42-S47, ESI $\dagger$ ). $T_{\mathrm{g} 1} \mathrm{~s}$ of $306{ }^{\circ} \mathrm{C}$ and $303{ }^{\circ} \mathrm{C}$ for $\mathrm{a}_{\mathrm{m}}\left[\mathrm{Zn}(\mathrm{Im})_{1.65}(\mathrm{ClbIm})_{0.35}\right]$ and $\mathrm{a}_{\mathrm{m}}\left[\mathrm{Zn}(\mathrm{Im})_{1.70}\right.$ $\left.(\mathrm{ClbIm})_{0.30}\right]$ were found respectively. Heat treatment of both samples at $450{ }^{\circ} \mathrm{C}$ however yielded $T_{\mathrm{g} 2} \mathrm{~S}$ of $324^{\circ} \mathrm{C}$ and $321{ }^{\circ} \mathrm{C}$, i.e. the expected $T_{\mathrm{g}}$ values for melt-quenched glasses with these compositions, based on the trend in $T_{\mathrm{g}}$ values as a function of the linker ratio (Fig. S46, ESI $\dagger$ ). TMA of $\mathrm{a}_{\mathrm{m}}\left[\mathrm{Zn}(\mathrm{Im})_{1.65}\right.$ $\left.(\mathrm{ClbIm})_{0.35}\right]$ indicated a $T_{\mathrm{s}}$ of $332{ }^{\circ} \mathrm{C}$, further confirming the glassy behaviour of $\mathrm{a}_{\mathrm{m}}$ ZIF-UC-5 (Fig. S47, ESI $\dagger$ ). As with $\mathrm{a}_{\mathrm{m}}$ ZIF62 , PDF analysis showed the retention of the $\mathrm{Zn}-\mathrm{Im}-\mathrm{Zn}$ unit upon amorphisation and loss of long-range order, in both $\mathrm{a}_{\mathrm{m}}$ ZIF-UC-5 samples (Fig. S48-S51, ESI $\dagger$ ).

In conclusion, we demonstrate formation of amorphous ZIF-62 and ZIF-UC- 5 directly by mechanochemical reaction. These $\mathrm{a}_{\mathrm{m}} \mathrm{ZIFs}$ exhibit $T_{\mathrm{g}} \mathrm{s}$ upon heat treatment, even though they have not been melt-quenched. This presents an alternate route to glassy ZIFs which circumvents the requirement to melt-quench a crystalline material to form a glass. These $\mathrm{a}_{\mathrm{m}}$ ZIFs have $T_{\mathrm{g}}$ values lower than expected, however heat treating them to agglomerate particles, results in $T_{\mathrm{g}}$ values consistent with $\mathrm{a}_{\mathrm{g}} \mathrm{ZIFs}$. Further to this the upper limit of bIm content in $\mathrm{a}_{\mathrm{m}}$ ZIF-62 was determined. By formation of $\mathrm{a}_{\mathrm{m}}\left[\mathrm{Zn}(\mathrm{Im})_{1.0}(\mathrm{bIm})_{1.0}\right]$, the highest bIm content ZIF glass to date, we have extended the $\mathrm{a}_{\mathrm{g}} \mathrm{ZIF}-62$ chemical space up to a composition of $\left[\mathrm{Zn}(\mathrm{Im})_{2-x}(\mathrm{bIm})_{x}\right]$ where $0.05 \leq x \leq 1$ and produced the ZIF glass with the highest $T_{\mathrm{g}}$ identified so far. This mechanochemical amorphisation method to form glassy ZIFs demonstrates a route to a wider variety of glass-forming systems not seen previously and removes the requirement for meltquenching crystalline materials.

\section{Conflicts of interest}

There are no conflicts to declare.

\section{References}

1 H.-C. Zhou, J. R. Long and O. M. Yaghi, Chem. Rev., 2012, 112, 673-674.

2 B. Li, H. M. Wen, W. Zhou and B. Chen, J. Phys. Chem. Lett., 2014, 5, 3468-3479.
3 H. X. Zhang, M. Liu, T. Wen and J. Zhang, Coord. Chem. Rev., 2016, 307, 255-266.

4 T. D. Bennett, J. C. Tan, Y. Yue, E. Baxter, C. Ducati, N. J. Terrill, H. H. M. Yeung, Z. Zhou, W. Chen, S. Henke, A. K. Cheetham and G. N. Greaves, Nat. Commun., 2015, 6, 1-7.

5 L. Frentzel-Beyme, M. Kloß, P. Kolodzeiski, R. Pallach and S. Henke, J. Am. Chem. Soc., 2019, 141, 12362-12371.

6 T. To, S. S. Sørensen, M. Stepniewska, A. Qiao, L. R. Jensen, M. Bauchy, Y. Yue and M. M. Smedskjaer, Nat. Commun., 2020, 11, 1-9.

7 C. Zhou, M. Stepniewska, L. Longley, C. W. Ashling, P. A. Chater, D. A. Keen, T. D. Bennett and Y. Yue, Phys. Chem. Chem. Phys., 2018, 20, 18291-18296.

8 A. Qiao, H. Tao, M. P. Carson, S. W. Aldrich, L. M. Thirion, T. D. Bennett, J. C. Mauro and Y. Yue, Opt. Lett., 2019, 44, 1623.

9 M. A. Ali, J. Ren, T. Zhao, X. Liu, Y. Hua, Y. Yue and J. Qiu, ACS Omega, 2019, 4, 12081-12087.

10 M. F. Thorne, M. L. R. Gómez, A. M. Bumstead, S. Li and T. D. Bennett, Green Chem., 2020, 22, 2505-2512.

11 R. Gaillac, P. Pullumbi and F. X. Coudert, J. Phys. Chem. C, 2018, 122, 6730-6736.

12 L. C. Zhang, Z. Q. Shen and J. Xu, Mater. Sci. Eng., A, 2005, 394, 204-209.

13 N. S. Trasi and S. R. Byrn, AAPS PharmSciTech, 2012, 13, 772-784.

14 W. Chen, S. Horike, D. Umeyama, N. Ogiwara, T. Itakura, C. Tassel, Y. Goto, H. Kageyama and S. Kitagawa, Angew. Chem., Int. Ed., 2016, 55, 5195-5200.

15 W. Chen, S. Horike, D. Umeyama, N. Ogiwara, T. Itakura, C. Tassel, Y. Goto, H. Kageyama and S. Kitagawa, Angew. Chem., Int. Ed., 2016, 55, 5195-5200.

16 T. D. Bennett, S. Cao, J. C. Tan, D. A. Keen, E. G. Bithell, P. J. Beldon, T. Friscic and A. K. Cheetham, J. Am. Chem. Soc., 2011, 133, 14546-14549.

17 S. Cao, T. D. Bennett, D. A. Keen, A. L. Goodwin and A. K. Cheetham, Chem. Commun., 2012, 48, 7805-7807.

18 A. M. Bumstead, M. F. Thorne and T. D. Bennett, Faraday Discuss., 2021, 225, 210-225.

19 L. Frentzel-Beyme, M. Kloß, R. Pallach, S. Salamon, H. Moldenhauer, J. Landers, H. Wende, J. Debus and S. Henke, J. Mater. Chem. A, 2019, 7, 985-990.

20 Y. Zhang, R. D. Adams and L. F. M. Da Silva, J. Adhes., 2014, 90, 327-345.

21 Y. Yang, C. J. Wilkinson, K. H. Lee, K. Doss, T. D. Bennett, Y. K. Shin, A. C. T. Van Duin and J. C. Mauro, J. Phys. Chem. Lett., 2018, 9, 6985-6990.

22 M. L. Ríos Gómez, G. I. Lampronti, Y. Yang, J. C. Mauro and T. D. Bennett, Dalton Trans., 2020, 49, 850-857.

23 A. M. Bumstead, M. L. Ríos Gómez, M. F. Thorne, A. F. Sapnik, L. Longley, J. M. Tuffnell, D. S. Keeble, D. A. Keen and T. D. Bennett, CrystEngComm, 2020, 22, 3627-3637.

24 A. Qiao, T. D. Bennett, H. Tao, A. Krajnc, C. M. Doherty, A. W. Thornton, J. C. Mauro, G. N. Greaves and Y. Yue, Sci. Adv., 2018, 4, 1-8.

25 V. Nozari, C. Calahoo, L. Longley, T. D. Bennett and L. Wondraczek, J. Chem. Phys., 2020, 153, 204501.

26 R. N. Widmer, G. I. Lampronti, S. Chibani, C. W. Wilson, S. Anzellini, S. Farsang, A. K. Kleppe, N. P. M. Casati, S. G. Macleod, S. A. T. Redfern, F. X. Coudert and T. D. Bennett, J. Am. Chem. Soc., 2019, 141, 9330-9337.

27 E. F. Baxter, T. D. Bennett, A. B. Cairns, N. J. Brownbill, A. L. Goodwin, D. A. Keen, P. A. Chater, F. Blanc and A. K. Cheetham, Dalton Trans., 2016, 45, 4258-4268.

28 D. A. Keen and T. D. Bennett, Phys. Chem. Chem. Phys., 2018, 20, 7857-7861.

29 J. Hou, M. L. Ríos Gómez, A. Krajnc, A. McCaul, S. Li, A. M. Bumstead, A. F. Sapnik, Z. Deng, R. Lin, P. A. Chater, D. S. Keeble, D. A. Keen, D. Appadoo, B. Chan, V. Chen, G. Mali and T. D. Bennett, J. Am. Chem. Soc., 2020, 142, 3880-3890.

30 J. Yang, Y. B. Zhang, Q. Liu, C. A. Trickett, E. Gutiérrez-Puebla, M. Á. Monge, H. Cong, A. Aldossary, H. Deng and O. M. Yaghi, J. Am. Chem. Soc., 2017, 139, 6448-6455. 